\title{
Lucha facciosa, autonomía e influencias externas en las Fuerzas Armadas argentinas en la segunda mitad del siglo $\mathrm{XX}$
}

\section{Factional struggle, autonomy and external influences in Argentine Armed Forces in the second half of the twentieth century}

\author{
Daniel Mazzei \\ Universidad de Buenos Aires \\ Instituto Interdisciplinario de Estudios e \\ Investigaciones de América Latina, Argentina \\ danielhmazzei@gmail.com
}

\begin{abstract}
Resumen
A partir de "Revolución Libertadora" (1955-1958) las Fuerzas Armadas se transformaron en protagonistas del proceso político argentino. Se inició entonces la "desperonización" de las instituciones militares, tal como ocurrió en otros espacios de la sociedad civil. La etapa posrevolucionaria se caracterizó por las luchas facciosas, la indisciplina, la falta de subordinación a las jerarquías, el quiebre de la cadena de mandos, y el aumento de los niveles de autonomía militar frente al poder político. Además, la llegada de una misión de asesores franceses, en 1957, significó el inicio de profundos cambios en materia de doctrina de defensa.

El presente artículo propone analizar la situación de las Fuerzas Armadas argentinas a lo largo de tres décadas a partir de tres ejes que marcan el período iniciado en 1955: la lucha entre facciones que determina enormes purgas al interior de las instituciones militares, la creciente influencia doctrinaria externa (tanto francesa como norteamericana), y el proceso de autonomía militar del poder civil que alcanzó su máxima expresión a finales de la década de 1970.
\end{abstract}

\section{Palabras claves}

Fuerzas Armadas; autonomía militar; seguridad interna; Argentina contemporánea 


\begin{abstract}
From "Revolución Libertadora" (1955-1958) Armed Forces became protagonists of the argentine political process. Then began the "desperonization" of military institution, similar to what happened in other areas of civil society. Postrevolutionary era was characterized by factional struggles, indiscipline, lack of subordination to hierarchies, breakdown of the chain of command and increased levels of military autonomy. In addition, the arrival of a mission of French advisers, in 1957, meant the beginning of profound changes in the field of defense doctrine.

The present article proposes to analyse the situation of the Argentine Armed Forces over three decades starting from three axes that mark the period begun in 1955: the struggle between factions that determined huge purges within the military institutions, the growing external doctrinal influence (both French and American), and the increases of military autonomy of the civil power that reached its peak in the late 1970 s.
\end{abstract}

\title{
Keywords
}

Armed Forces; military autonomy; internal security; contemporary Argentina 


\section{Lucha facciosa, autonomía e influencias externas en las Fuerzas Armadas argentinas en la segunda mitad del siglo $X X$}

\section{Introducción}

La "Revolución Libertadora” (1955-1958) representó un punto de inflexión en el proceso político argentino, y un corte abrupto en la historia de sus Fuerzas Armadas, que se transformaron en protagonistas del mismo. Como una reacción de algunos sectores militares contra el intento de "peronizar" a las Fuerzas Armadas, el triunfo de la "Revolución Libertadora" inició un proceso inverso de "desperonización", similar al que ocurrió en otros espacios de la sociedad civil, durante el cual centenares de oficiales fueron pasados a retiro obligatorio. La etapa posrevolucionaria se caracterizó, además, por las luchas facciosas, la indisciplina, la falta de subordinación a las jerarquías, el quiebre de la cadena de mandos, y el aumento de los niveles de autonomía militar frente al poder político. Esta situación se prolongó hasta septiembre de 1962, cuando la victoria de la facción azul, preocupada por la supervivencia de la institución, inició una década de orden al interior del Ejército que estuvo dominado por un grupo homogéneo de oficiales superiores. La mayoría de ellos compartían un pasado de luchas antiperonistas, habían sido reincorporados durante la "Revolución Libertadora", y restablecieron los patrones de disciplina y autoridad jerárquica al tiempo que controlaron, a través de manejo de los ascensos, retiros y traslados, los puestos claves de la estructura de mandos del Ejército hasta mayo de 1973.

El presente artículo propone analizar la situación de las Fuerzas Armadas argentinas a lo largo de tres décadas a partir de tres ejes que marcan el período iniciado en 1955: la lucha entre facciones que determina enormes purgas al interior de las instituciones militares, la creciente influencia doctrinaria externa (tanto francesa como norteamericana) que significó un profundo cambio en la doctrina de defensa, y el proceso de autonomía militar del poder civil que alcanzó su máxima expresión a finales de la década de 1970.

\section{Autonomía militar}

Durante los primeros años de la presidencia de Perón las Fuerzas Armadas lograron un alto nivel de profesionalización, se concentraron en sus funciones específicas, y se subordinaron al poder político. A ello contribuyó el desarrollo de la Doctrina de Defensa Nacional (DDN), ya preanunciada por Perón en su famoso discurso al inaugurar la cátedra de Defensa Nacional en la Universidad de La Plata, en junio de 1944. ${ }^{1}$ En esa oportunidad Perón desarrolló el concepto de "Nación en armas" que implicaba la necesidad de un desarrollo industrial autónomo que asegurara la autarquía en materia de abastecimientos militares. La nueva doctrina tuvo amplio apoyo entre los militares nacionalistas por su pertinencia militar: la

\footnotetext{
${ }^{1}$ Para un completo análisis del discurso de Perón véase Ernesto López, El primer Perón. El militar antes que el político. Buenos Aires, Capital intelectual, 2009, capítulo 5.
} 
congruencia entre su concepción de la guerra y su concepción de Nación requería de los militares simplemente identificaciones profesionales. ${ }^{2}$

Fueron años de aumento del gasto militar que permitieron la construcción de nuevos cuarteles, grandes maniobras, y compra de armamento a Gran Bretaña y los Estados Unidos. Durante el primer mandato de Perón un buen profesional podía ascender sin problemas, aunque no fuera oficialista. Alcanzaba con que fuera un buen militar. ${ }^{3}$ Sin embargo, hacia 1950 , cuando se inicia el proceso de peronización de la sociedad, no ser peronista comenzó a ser un obstáculo. La política entró a los cuarteles a través de un programa de adoctrinamiento nacional, basado en la doctrina Justicialista. También, a través del Servicio de Informaciones del Ejército (SIE), se desarrollaron mecanismos de espionaje hacia los opositores y se fomentó la delación. Paralelamente, la oposición comenzó a conspirar e intentó un fallido golpe de Estado en septiembre de 1951, poco antes de la reelección de Perón. ${ }^{4}$ La respuesta fue la declaración del "estado de guerra interno", las purgas y la cárcel para más de cien oficiales del Ejército y la Aeronáutica.

Perón intentó, en términos de Samuel Huntington, el control civil subjetivo de los militares, subordinándolos "sobre la base de la adhesión particularista de los uniformados a algún grupo o sector político civil"5. En este caso se trataba de transformarlos en parte del Movimiento Nacional Justicialista. Sin embargo, la subordinación es un objetivo de las autoridades políticas que, en algunas oportunidades, puede producir reacciones contrarias a las esperadas, reforzando "[...] una tendencia a la politización autónoma de los uniformados y a un incremento de su capacidad para proyectarse sobre la escena política de manera autónoma, a partir de consideraciones y criterios propios". ${ }^{6}$

La contracara del control civil es la autonomía militar, entendida como la pérdida relativa de subordinación de las autoridades militares al poder político que las conduce a un incremento de su insularidad y a su aislamiento respecto de otras esferas del Estado y la Sociedad. ${ }^{7}$ David Pion Berlin sostiene que la autonomía

\footnotetext{
2 Ernesto López, Seguridad nacional y sedición militar. Buenos Aires, Legasa, 1987, p. 89.

${ }^{3}$ Un buen ejemplo es el de Alejandro A. Lanusse quien se manifestó contrario a las políticas del gobierno peronista desde un primer momento y ascendió sin inconvenientes hasta su participación en la fallida revolución del general Benjamín Menéndez, en 1951.

${ }^{4}$ El fallido intento golpista del 28 de septiembre de 1951 fue encabezado por el general Benjamín Menéndez. La mayoría de los implicados eran tenientes y capitanes del arma de caballería que fueron a las prisiones de Rawson y Río Gallegos. Sobre las carreras posteriores a 1955 de muchos de estos militares véase Ernesto López, Seguridad nacional..., Op.Cit., pp. 120-126.

${ }^{5}$ Ernesto López y David Pion Berlin, Democracia y cuestión militar. Bernal, Universidad Nacional de Quilmes, 1996, p.153. Según López los motivos de esta adhesión particularista podrían ser: la identidad o semejanza de opiniones, la lealtad personal, la conveniencia material institucional o individual, entre otras. La consecuencia es que las instituciones militares se civilinizan (o sea que asumen ciertas características y dinámicas no militares sino cívico/políticas) y se politizan. Ernesto López, Ni la ceniza ni la gloria. Actores, sistema político y cuestión militar en los años de Alfonsín. Bernal, Universidad Nacional de Quilmes, 1994, pp.22-23.

${ }^{6}$ Ernesto López, Ni la ceniza..., Op.Cit., p.26.

${ }^{7}$ Ibidem. Para el coronel español Prudencio García, la autonomía militar se manifiesta en [...] la sólida convicción instalada en las mentes de gran número de militares argentinos [...] en el sentido de que pueden y deben intervenir en las grandes cuestiones de la política nacional, juzgando, valorando y
} 


\section{Lucha facciosa, autonomía e influencias externas en las Fuerzas Armadas argentinas en la segunda mitad del siglo $\mathrm{XX}$}

militar tiene una finalidad defensiva y otra ofensiva. ${ }^{8}$ La primera está dirigida a proteger a la institución militar de las intromisiones políticas. La autonomía ofensiva se produce cuando los militares quieren extender sus prerrogativas más allá del ámbito castrense y condicionan la acción del gobierno. La finalidad defensiva puede vincularse con lo que el propio Pion Berlin llama dimensión profesional (o institucional) referida a la independencia y exclusividad profesional de los militares que buscan preservarse a sí mismos de una intromisión política "excesiva", la que, según creen, puede interferir en las metas de profesionalización y modernización.

Los intentos de control civil subjetivo a través de la peronización de las Fuerzas Armadas provocaron una reacción que se expresó en el quiebre horizontal de la cadena de mandos cuando el gobierno se enfrentó a la Iglesia Católica, en 1955. La politización que se había iniciado a comienzos de la década se profundizó, aunque con signo inverso, tras el derrocamiento de Perón, mediante un profundo proceso de depuración castrense que desarrollaremos en el siguiente apartado.

A partir de entonces los militares expandieron sus esferas de influencia hasta absorber funciones previamente desempeñadas por lo que percibían como gobiernos débiles. El nivel de autonomía política de los militares tuvo avances y retrocesos. Sin embargo, la autonomía plena (o "corporatización") que se manifiesta cuando las instituciones militares tienen capacidad para definir por sí mismas, sus objetivos, su doctrina, su estructura orgánica y su relación con otros actores políticos y sociales, solo alcanzó su punto culminante a partir de 1975, y se prolongó durante el autodenominado "Proceso de Reorganización Nacional".

A partir de septiembre de 1955 es posible detectar coyunturas políticoinstitucionales en las cuales las dimensiones y niveles de autonomía se modificaron dramáticamente. Los primeros cambios se produjeron cuando Arturo Frondizi designó a sus primeros Secretarios Militares (mayo de 1958) provocando la reacción de los sectores castrenses más recalcitrantes, conocidos como "gorilas". La autonomía comenzó entonces a manifestarse a través de planteos, siempre en el marco "institucional", esto es vinculados a la situación interna de las Fuerzas Armadas. Poco más de un año después, Frondizi había cedido a las presiones y “entregado" a sus primeros Secretarios Militares. ${ }^{9}$ En septiembre de 1959, luego de un planteo realizado por el general Carlos S. Toranzo Montero, la autonomía pasó de la dimensión institucional a la política. El pedido de renuncia al gobernador ucrista de Córdoba (1960), o el cambio de política exterior hacia Cuba (febrero de

\footnotetext{
decidiendo su mayor o menor concordancia con los `intereses de la Patria'"; y en "la convicción, igualmente firme, de que cuando la actuación del gobierno constitucional no responde a esas expectativas y se aparta demasiado de ellas, el estamento militar puede y debe actuar sobre aquel en todos los grados posibles: desde la fuerte presión estamental hasta el golpe de Estado militar". Prudencio García, El drama de la autonomía militar. Buenos Aires, Alianza,1995, p. 351.

8 David Pion Berlin, "Autonomía militar y democracias emergentes en América del Sur”, en Ernesto López y David Pion Berlin, Democracia..., Op.Cit., p.15.

9 Para un desarrollo de las crisis militares durante la presidencia de Arturo Frondizi véase Robert Potash, El Ejército y la política en Argentina (1945-1962). Buenos Aires, Sudamericana, 1981; y Rosendo Fraga, El Ejército y Frondizi (1958-1962). Buenos Aires, Emecé, 1992.
} 
1962), son un buen ejemplo de ello. Este cambio fue el resultado de un doble movimiento: por un lado, la acción de los militares; por otro, la omisión del gobierno y de la dirigencia política que cedieron posiciones frente a la presión castrense. Desde 1955 las fuerzas políticas del campo antiperonista fueron cómplices de la creciente autonomía castrense porque alentaron y legitimaron la politización de los militares y la militarización de la política. La actitud de la clase política de reclamar y/o legitimar las intervenciones de las Fuerzas Armadas ("Golpear la puerta de los cuarteles") alentó a los militares a pasar de la autonomía institucional a la autonomía política.

Durante la presidencia provisional del senador José María Guido la cuestión de la autonomía se manifestó a través de las posturas de los generales Benjamín Rattembach y Juan C. Onganía en torno al rol que debían cumplir los Secretarios Militares. Rattembach, secretario de Guerra, se consideraba un representante del presidente Guido, en quien las Fuerzas Armadas habían delegado la soberanía. Onganía, por el contrario, concebía a los Secretarios Militares como representantes de su fuerza ante el Poder Ejecutivo, que cumplían funciones exclusivamente administrativas y políticas, y no debían inmiscuirse en la conducción efectiva de la Institución. Para Onganía el Secretario de Guerra era un subordinado (y no al revés), y esto debía ser así para eliminar las influencias políticas sobre el Ejército. Lo que los enfrentaba era la opuesta concepción sobre la autonomía militar que tenían ambos generales. Para Onganía, el poder militar (el Comandante en Jefe) estaba por sobre el poder político (el Secretario). En sus memorias inéditas Rattembach afirma que Onganía "no veía el grave peligro que entrañaba tal solución para el estado al convertir a la Fuerza Armada en un instrumento autónomo, sin que nadie lo controlara"10. Rattembach comprendía que la posición del Comandante en Jefe conducía, en última instancia, a la autonomía plena del poder militar. La concepción de Onganía sobre la función del Secretario de Guerra está en la base del conflicto que determinaría su pase a retiro en noviembre de 1965.11

El triunfo de la facción azul, liderada por Onganía, y la entrega del gobierno a los radicales del pueblo, en octubre de 1963, con la figura de un ministro de Defensa fuerte (Leopoldo Suárez) y una política exterior independiente, significaron un límite a la autonomía militar. No obstante una serie de sucesos permiten establecer el punto de equilibro alcanzado. En ese sentido, la decisión del presidente Illia de no enviar un contingente militar a Santo Domingo (mayo de 1965) fue, a los ojos castrenses, una intromisión y un avance del poder político en un tema vinculado a

\footnotetext{
10 Citado en Robert Potash, El Ejército y la política en Argentina, t.3. Buenos Aires, Sudamericana, 1994, p. 105.

${ }^{11}$ Entre octubre de 1963 y octubre de 1965 se desempeñó como Secretario de Guerra el general Ignacio Ávalos, que había pasado a retiro en 1956. Tras su renuncia por diferencias políticas y personales insalvables con Onganía, el presidente Illia designó a un general en actividad, Eduardo Castro Sánchez. Onganía no aceptó que el Poder Ejecutivo designara a un general más moderno que él y pidió su retiro. Su argumento era falaz ya que existían varios ejemplos de oficiales modernos que ocuparon cargos similares al de Secretario de Guerra, como los coroneles Manuel Rodríguez o Juan Domingo Perón.
} 


\section{Lucha facciosa, autonomía e influencias externas en las Fuerzas Armadas argentinas en la segunda mitad del siglo $\mathrm{XX}$}

la seguridad continental. Asimismo, la resolución de la crisis que culminó con el retiro del general Jorge Rosas por parte de Onganía ${ }^{12}$, y las posiciones adoptadas por las Fuerzas Armadas en política exterior (crisis de Santo Domingo o conflicto limítrofe de Laguna del Desierto) muestran el alto grado de injerencia castrense, más allá de las decisiones finales del gobierno radical del pueblo.

La primera etapa de la "Revolución Argentina" significó otro ligero retroceso en el nivel de autonomía que se expresó en la frase "las Fuerzas Armadas no gobiernan ni co-gobiernan". Los militares otorgaron carta blanca al presidente Onganía. El relevo del general Pascual Pistarini, en diciembre de 1966, es un claro indicador de que la autoridad presidencial [el poder político] había avanzado sobre una de las prerrogativas de la autonomía militar: el control de los ascensos y destinos. En otro gesto de autoridad, el presidente Onganía pasó a retiro, en agosto de 1968, a los tres Comandantes en Jefe que lo habían encumbrado a la primera magistratura. No obstante, la designación al frente del Ejército de un ambicioso caudillo militar (Alejandro Lanusse) y el deterioro de la situación política y social marcaron el comienzo de una nueva fase ascendente de la autonomía militar. La intervención directa del Ejército en Rosario y la posterior ocupación de la ciudad de Córdoba (mayo de 1969), acompañadas por el discurso del general Lanusse del 29 de mayo de 1969, revelan que las Fuerzas Armadas habían decidido no ser espectadoras pasivas del deterioro acelerado del proceso político. ${ }^{13} \mathrm{El}$ año que transcurre entre el "Cordobazo” y el derrocamiento de Onganía (junio de 1970) no debe interpretarse como el enfrentamiento personal entre dos caudillos por el control de una institución sino que marca la tensión entre un Presidente que se cree investido de un mandato casi divino y Fuerzas Armadas que buscan transformarse en protagonista del devenir político, e imponer una salida electoral controlada a mediano plazo.

Durante la breve gestión del general Roberto Levingston el poder militar avanzó frente al poder político, a tal punto que el Presidente inició su gobierno con ministros designados por la Junta de Comandantes en Jefe. Su elección había sido un intento fallido por mantener ambos poderes separados. Su derrocamiento fue el reconocimiento de un fracaso. La unificación de las figuras del Presidente y del Comandante en Jefe en el general Alejandro Lanusse significó una concentración de poder inédita luego de 1955.

En ese contexto, el casi seguro triunfo del Frente Justicialista de Liberación en las elecciones de marzo de 1973 preocupaba a las Fuerzas Armadas. Sus máximas autoridades eran conscientes de que la llegada de un gobierno peronista afectaría los niveles de autonomía militar alcanzados. Esos temores se reflejan en la redacción

\footnotetext{
12 Sobre el retiro de Rosas por presión de Onganía véase Daniel Mazzei, Bajo el poder de la caballería. El Ejército Argentino (1962-1973). Buenos Aires, Eudeba, 2012, pp.111-114.

13 El 29 de mayo de 1969, en Campo de Mayo, Lanusse afirmó: "El proceso no permite ya la presencia de espectadores. Necesita que todos seamos actores, partícipes decididos de esta gran obra nacional, porque así lo reclama el futuro de nuestros hijos. (...) El Comandante en Jefe adquiere el compromiso de proveer las soluciones que sean necesarias". La Nación, 30 de mayo de 1969.
} 
de un documento conocido como "de los Cinco Puntos"14, que representan un claro intento de resistir cualquier avance del poder político, o al menos de establecer cuáles serían los límites tolerables de injerencia por parte del gobierno constitucional. La magnitud del triunfo de la fórmula Cámpora-Solano Lima significó un claro fracaso de la estrategia de la conducción lanussista, y provocó un marcado repliegue de la autonomía militar.

Los primeros meses de la gestión peronista estuvieron marcados por un comandante en jefe, Jorge Carcagno, que se subordinó a los lineamientos políticos e ideológicos del presidente Cámpora. ${ }^{15}$ El giro derechista impuesto por Perón a partir del octubre de 1973 puso fin a la novedosa experiencia de Carcagno. Tras su relevo, $\mathrm{y}$ frente al accionar de las organizaciones guerrilleras, las Fuerzas Armadas obtuvieron, paulatinamente, mayores atribuciones de parte del general Perón y, luego, de su viuda. Esta escalada alcanzó su punto culminante con el "Operativo Independencia" y los decretos firmados por Isabel Perón y su gabinete para "aniquilar" el accionar guerrillero. ${ }^{16}$ Para entonces la Presidente ya había designado a un reconocido antiperonista, el general Jorge Videla, al frente del Ejército, cediendo ante presiones corporativas su potestad de designar a las autoridades militares. En diciembre de 1975, durante la represión al ataque guerrillero al cuartel de Monte Chingolo, se hizo evidente que las Fuerzas Armadas había alcanzado el punto máximo de su autonomía frente al poder político, que Ernesto López ha caracterizado como "corporatización". ${ }^{17}$

Esta situación se prolongó hasta junio de 1982. La derrota en la Guerra de las Malvinas marcó el comienzo de la transición democrática. Si bien los militares en el poder intentaron clausurar el pasado con su "Informe Final" y, posteriormente, con una ley de autoamnistía, el proceso de transición por colapso era imparable, y debieron iniciar la apertura política y convocar a elecciones anticipadamente, en octubre de $1983 .{ }^{18}$

\footnotetext{
${ }^{14} \mathrm{El} \mathrm{"Compromiso} \mathrm{de} \mathrm{conducta} \mathrm{que} \mathrm{el} \mathrm{Ejército} \mathrm{Argentino} \mathrm{asume} \mathrm{hasta} \mathrm{el} 25$ de mayo de 1977" era un documento que debían firmar todos los generales en actividad por el cual el Ejército se presentaba como garante del proceso político; proponía asegurar la continuidad del Poder Judicial establecido por la dictadura; rechazaba una posible amnistía; e intentaba asegurar la sucesión de Lanusse al frente del Ejército. Sólo el general Ibérico Saint Jean se negó a firmar el documento.

${ }^{15}$ Sobre la particular experiencia del general Carcagno al frente del Ejército entre mayo y diciembre de 1973 véase Daniel Mazzei, “Carcagno, el Comandante que no fue”, Cuadernos del Sur n40 (2011), pp.139-157.

${ }_{16}$ El 5 de febrero de 1975 Isabel Perón firmó el decreto 261/75 que autorizaba al Comando del Ejército a "neutralizar y/o aniquilar" el accionar guerrillero en la provincia de Tucumán, en el marco del denominado "Operativo Independencia". El 6 de octubre de ese año el decreto 2772/75, firmado por el senador Ítalo Luder y todo el gabinete, extendió a todo el país las facultades otorgadas a las Fuerzas Armadas por el decreto 261/75.

17 “La corporatización (...) involucra la autonomización; alude a un grado avanzado de ésta, en el que las instituciones militares han alcanzado una discernible autonomía en materia de funcionamiento y decisiones. En el estadío corporativo, las instituciones militares tienen capacidad para definir desde sí mismas sus fines y misiones, su doctrina, su orgánica, sus modos de relación con el mundo de la política, etc. (...) Sería, así, prácticamente sinónimo de aquello que el lenguaje común tendió a designar con el nombre de "partido militar"'. Ernesto López , Ni la ceniza..., Op.Cit., p. 53.

${ }^{18}$ Ver Daniel Mazzei, "Relexiones sobre la transición democrática argentina", PolHis, $\mathrm{N}^{\circ} 7$ (primer semestre de 2011), pp.8-15.
} 


\section{Lucha facciosa, autonomía e influencias externas en las Fuerzas Armadas argentinas en la segunda mitad del siglo $\mathrm{XX}$}

Con la asunción de Raúl Alfonsín, en diciembre de 1983, algunos creyeron que se terminaría con el entonces debilitado poder militar. Sin embargo lograr la subordinación militar al poder civil sería un trabajo largo, complicado y riesgoso. Las primeras medidas tomadas por el nuevo gobierno marcaron un avance en ese aspecto. ${ }^{19}$ Debilitados, los militares cedieron parte de su autonomía. Sin embargo los levantamientos castrenses que sufrió el presidente Alfonsín mostraron la tensión entre un gobierno que intentaba imponer el control civil y fuerzas armadas que lo resistían, buscando mantener altos niveles de autonomía. Desgastado después de cuatro años de gobierno, Alfonsín debió ceder parcialmente a las presiones. Sin embargo, durante su gobierno se inició un sensible avance en el control civil, que se profundizaría en las décadas siguientes.

\section{Lucha facciosa}

El período iniciado en 1955 se caracterizó, además de la creciente autonomía militar del poder civil, por las profundas disputas al interior de las instituciones armadas: lucha facciosa, indisciplina, insubordinación y ruptura de la cadena de mandos. Algunos lo han explicado como consecuencia de las purgas y reincorporaciones ocurridas durante la "Revolución Libertadora". La desperonización de las Fuerzas Armadas significó el retiro obligatorio de cientos de oficiales y suboficiales que dejaron grandes vacíos escalafonarios. Estos fueron ocupados por decenas de oficiales reincorporados durante los primeros meses del gobierno revolucionario y designados en destinos destacados, lo que generó disputas entre los que permanecieron en actividad y aquellos que estuvieron presos o debieron emigrar. En los años posteriores se manifestó un relajamiento de los elementos básicos en toda fuerza armada: la disciplina y la subordinación. El almirante Jorge Perren lo expresó claramente: “el grado ya no alcanzaba para imponer la subordinación, y los méritos revolucionarios se privilegiaban a las capacidades profesionales a la hora de establecer los ascensos" 20 .

A comienzos de 1956, "tribunales especiales", integrados -en su mayoría- por oficiales reincorporados, extendieron la purga hacia los grados inferiores. En ese contexto en febrero de 1956 fueron pasados a retiro obligatorio 180 jefes y oficiales superiores. Además, a partir de la Orden de Operaciones 44 la depuración se extendió a los suboficiales que constituían el sector más leal a Perón. Los castigos no sólo significaron el retiro de muchos oficiales y suboficiales, sino el "destierro" a

\footnotetext{
${ }^{19}$ A partir de diciembre de 1983 el Parlamento volvió a tener autoridad en la designación de los oficiales superiores; se designó a un ministro de Defensa que no era un mero intermediario sin poder de decisión; Fabricaciones Militares pasó a depender directamente del área de Defensa, al igual que Prefectura y gendarmería; y se redujo el presupuesto militar del 4,6\% al 2,6\% del PBI, entre otras medidas. Sin embargo el hecho más importante en materia de control civil fue la decisión de juzgar a los máximos responsables del gobierno militar. Se trató de una decisión inédita, ya que nunca un gobierno civil y democrático había juzgado a los máximos responsables de una dictadura.

${ }^{20}$ Jorge Perren, Puerto Belgrano y la Revolución Libertadora. Buenos Aires, Solaris editores, 1997, p. 302.
} 


\section{Daniel Mazzei}

guarniciones de frontera, o bien a destinos burocráticos, de muchos cuadros jóvenes considerados "recuperables". Durante la llamada "Revolución Libertadora" pasaron a retiro casi 500 oficiales del Ejército y más de 100 de cada una de las otras dos fuerzas. ${ }^{21}$

En 1956 también se produjeron nuevos enfrentamientos, pero ahora al interior de la facción vencedora, entre camarillas, por diferencias ideológicas y rivalidades personales. El derrocamiento del nacionalista Eduardo Lonardi por parte de la Marina y del sector liberal del Ejército abrió un nuevo foco de conflicto. El presidente Aramburu y su ministro de Guerra, Arturo Osorio Arana, relevaron a diecisiete generales a los que se calificaba como "nacionalistas", en noviembre de 1956. A partir de entonces, y durante todo 1957, el ministro Osorio Arana construyó una conducción de tendencia liberal, más homogénea, que contaba con el respaldo de la Marina de Guerra, encolumnada tras la férrea conducción del almirante Isaac Rojas.

Durante la presidencia de Arturo Frondizi (1958-1962) los sectores más intransigentes del antiperonismo (conocidos habitualmente como "gorilas") mantuvieron un lugar central de la mano del general Carlos S.Toranzo Montero. Para entonces el bloque liberal parecía dividido en dos fracciones entre los irreductibles a la participación del peronismo y aquellos, más moderados, que auspiciaban un legalismo condicionado, y apoyaban al Presidente pero establecían límites a su gestión. Las primeras disidencias se produjeron en torno a la designación de los Secretarios Militares por parte del Presidente. A partir de mayo de 1959 comenzaron a manifestarse signos de indisciplina, en particular en la poderosa $4^{\circ}$ División de Infantería de Córdoba. Los planteos del sector "gorila", liderado por el general Toranzo Montero, forzaron las renuncias de los Secretarios de Guerra Héctor Solanas Pacheco y Elbio Anaya, en 1959, y Rodolfo Larcher, en 1960. A partir de 1961 se fueron conformando dos facciones antagónicas, una liderada por el Comandante en Jefe Raúl Poggi, continuador de Toranzo Montero, y otra por el Secretario Rosendo Fraga, que se apoyaba en un grupo de coroneles de caballería de Campo de Mayo y defendía la continuidad de Frondizi.

La lucha facciosa se agravó tras el derrocamiento de Arturo Frondizi, en marzo de 1962, cuando un sector del Ejército se alió con la Marina para imponer la salida golpista, pero encontró resistencia en sectores del Ejército y la Aeronáutica. ${ }^{22}$ El coronel Juan F. Guevara, hombre clave durante la Revolución Libertadora, escribía en agosto de 1962:

“El desagradable rostro de la anarquía [...] comenzó a hacer pensar a más de uno, que nuestros problemas no eran solo de hombres. [...] En nuestra

\footnotetext{
21 Daniel Mazzei, "Tiempo de revancha: la desperonización del Ejército durante la Revolución Libertadora", en Taller, $\mathrm{N}^{\circ} 12$, abril de 2000.

22 Para los detalles del golpe contra Frondizi véase Eugenio Kvaternik, Crisis sin salvataje: la crisis político-militar de 1962-1963. Buenos Aires, Ides, 1987; y Rosendo Fraga, El Ejército y Frondizi..., Op.Cit.
} 


\section{Lucha facciosa, autonomía e influencias externas en las Fuerzas Armadas argentinas en la segunda mitad del siglo $X X$}

Argentina de 1962 las instituciones militares en cuanto cuerpos orgánicos dotados de un espíritu que las informa y les da la razón de ser, ya casi habían dejado de ser"23.

Tras meses de conflicto institucional, enfrentamiento larvado, y falta de acuerdo sobre cómo resolver la cuestión peronista, la crisis llega a su punto culminante entre agosto y septiembre de 1962. Se produjo entonces una reacción que Guillermo 0’Donnell caracteriza como "profesionalista" 24 , iniciada por algunos coroneles de caballería, que cristalizó en la formación de dos facciones, que habitualmente conocemos como azules y colorados. Finalmente, en septiembre de 1962 , las facciones se enfrentaron en una serie de escaramuzas que culminaron con el triunfo de los azules, liderados por el entonces desconocido general Juan $\mathrm{C}$. Onganía.

Las diferencias entre azules y colorados no estaban relacionadas con el grado de anticomunismo o antiperonismo de una u otra facción. Los azules estaban convencidos que la continuidad de la práctica facciosa debilitaría a las Fuerzas Armadas. Onganía lo expresaría en forma categórica: "Sin disciplina no hay jerarquía ni mando. Sin mando hay anarquía. La anarquía en el Ejército llevaría al caos a la Nación". ${ }^{25}$ No eran convicciones democráticas, como planteaban los comunicados de Campo de Mayo, o sus publicistas. La línea de ruptura no pasaba por cuestiones ideológicas de fondo sino por cuestiones coyunturales sobre la salida política. Los colorados estaban convencidos que había que eliminar al peronismo y establecer una dictadura de largo plazo. Los azules creían que los militares tenían que apartarse de la participación política que los dividía y enfrentaba entre sí, y quedarse como custodios de la democracia, con un rol tutorial del sistema político. ${ }^{26}$

En los meses finales de 1962, los vencedores, restablecen los patrones de disciplina y autoridad de la mano del general Onganía, a través de una purga de altos mandos colorados del Ejército. No obstante el conflicto no había finalizado ya que la Marina, que había adquirido un peso político inédito desde 1955, se mantenía como un bastión de los principios colorados. En abril de 1963 un nuevo movimiento armado, ahora encabezado por el almirante Rojas y el general Benjamín Menéndez, fue reprimido por las tropas azules del general Onganía.

El triunfo de la facción azul, preocupada por la supervivencia de la institución, inició una década de estabilidad, de orden al interior del Ejército, que se

\footnotetext{
${ }^{23}$ Juan Francisco Guevara, Argentina y su sombra. Buenos Aires, edición del autor, 1973, pp. 149, 153. ${ }^{24}$ Guillermo O’Donnell, "Modernización y golpes militares. Teoría, comparación y el caso argentino", Desarrollo Económico, Vol.12, N47, octubre-diciembre de 1972.

${ }^{25}$ La Nación, 2 de mayo de 1963.

${ }^{26}$ Un memorándum secreto del grupo golpista que circuló entre jefes y oficiales en mayo de 1966, y fue "filtrado" por Primera Plana, expresaba que el enfrentamiento "no respondió a que tuvieran una imagen distinta del país. Nació del enfrentamiento de dos concepciones diferentes acerca de la misión específica que incumbía a las Fuerzas Armadas en esa coyuntura". Primera Plana, Nㅜ176, 10 de mayo de 1966.
} 
consolidó como fuerza hegemónica. ${ }^{27}$ Los vencedores eran un grupo homogéneo de oficiales superiores que, integrado mayoritariamente por oficiales de caballería que compartían un pasado de luchas antiperonistas, controló el manejo de los ascensos, los retiros y los destinos hasta mayo de $1973 .^{28}$

Durante las comandancias de los generales Juan C. Onganía, Pascual Pistarini y Julio Alsogaray, todos oficiales de caballería, no se produjeron actos de indisciplina ni conflictos internos. Durante los años en los que Alejandro Lanusse estuvo al frente del Ejército consolidó una conducción a su imagen, integrada por muchos de los "revolucionarios del 51", probados en el antiperonismo, donde no siempre se tuvieron en cuenta los méritos profesionales. ${ }^{29}$

No obstante el control que ejercían Lanusse y el grupo de los "revolucionarios del 51" sobre el Alto Mando castrense, por debajo se fue gestando una corriente crítica que se manifestó durante el levantamiento de los regimientos de caballería de Azul y Olavarría, en octubre de 1971. Los militares rebeldes estaban unidos por su oposición a Lanusse, a las políticas económicas liberales y por su apoyo inicial al general Onganía. Representaban a las diferentes "familias" del nacionalismo argentino, lo que se manifestó en un discurso ecléctico y contradictorio en el cual se entremezclaban antiliberalismo, antiimperialismo, cristianismo y referencias a la Revolución Peruana de 1968. Si bien tras su fácil triunfo Lanusse descabezó el ala nacionalista del Ejército, la rebelión ocurrida entre la élite de la caballería mostró después de ocho años- grietas en conducción del Ejército y el surgimiento de grupos que simpatizaban con el peronismo entre los oficiales subalternos. ${ }^{30}$

El triunfo del FREJULI en marzo de 1973 marca el fin del predominio de la caballería. Lanusse es reemplazado por el general Jorge Carcagno, un oficial de infantería, que ha peleado en el bando colorado, de tendencia nacionalista. Durante su breve comandancia, Carcagno rompió con la estrategia política de sus antecesores y se alineó con la política del presidente Cámpora. Posiblemente el momento más destacado de su gestión fue el discurso que leyó en la Xº Conferencia de Ejércitos Americanos, en Caracas, donde criticó a los Ejércitos que actúan como guardias pretorianas, y manifestó que los enemigos que se debían combatir en nuestro continente eran el hambre y la pobreza. ${ }^{31}$ Su prematuro retiro, por decisión de Perón, excede el plano estrictamente castrense, y debe interpretarse en un plano más amplio: el del desplazamiento de aquellos dirigentes y grupos que habían

\footnotetext{
${ }^{27}$ Como consecuencia del enfrentamiento entre azules y colorados fueron pasados a retiro unos 400 oficiales del Ejército y más de 100 de la Armada. Además la Armada sufrió un recorte presupuestario y perdió los espacios institucionales que ocupaba desde septiembre de 1955.

28 Daniel Mazzei, “La élite del Ejército argentino (1962-1973)", Cuadernos de Marte / Año 3, № 4, julio 2013, págs. 93-125. http://webiigg.sociales.uba.ar/revistacuadernosdemarte/nro4/4_mazzei.pdf ${ }^{29}$ A fines de 1972, cuando se produjo el retorno de Perón al país, de los 10 generales de mayor graduación 7 habían participado en el intento revolucionario de 1951.

30 Daniel Mazzei, «Soldados de Perón. Los jóvenes oficiales del Ejército y el Peronismo durante la "Revolución Argentina"», Nuevo Mundo Mundos Nuevos [En ligne], Questions du temps présent, mis en ligne le 18 septembre 2015. URL: http://nuevomundo.revues.org/68192 ; DOI : 10.4000 /nuevomundo.68192

${ }^{31}$ Ver Daniel Mazzei, “Carcagno, el Comandante ...Op.Cit..
} 


\section{Lucha facciosa, autonomía e influencias externas en las Fuerzas Armadas argentinas en la segunda mitad del siglo $\mathrm{XX}$}

acompañado la línea política del presidente Cámpora en mayo de 1973, y habían establecido vínculos, más o menos estrechos, con Montoneros.

Carcagno fue sucedido por dos generales del arma de infantería y posturas cercanas al oficialismo (Leandro Anaya y Alberto Numa Laplane). Sin embargo, en agosto de 1975 la crisis provocada por la renuncia del todopoderoso ministro José López Rega arrastró al comandante Laplane. La presidente Isabel Perón cedió a las presiones corporativas y designó al general Jorge R. Videla en su reemplazo. Videla era un notorio antiperonista ${ }^{32}$, identificado con la tradición liberal del Ejército. Meses después el relevo del brigadier Fautario, comandante de la Fuerza Aérea, terminaría de conformar la Junta de Comandantes en Jefe que usurparía el poder en marzo de 1976. Con Videla se iniciaba una larga década dominada por oficiales pertenecientes a la tradición liberal formados luego de la "Revolución Libertadora" bajo el influjo doctrinario francés y norteamericano.

\section{Cambios doctrinarios}

El crecimiento en el nivel de autonomía militar desarrollado más arriba se vio favorecido por la profunda transformación doctrinaria de las Fuerzas Armadas que comenzó hacia 1957 con la llegada de un grupo de instructores franceses a la Escuela Superior de Guerra. ${ }^{33}$ Según Ernesto López, tras el derrocamiento de Perón, el sector liberal del Ejército buscó reemplazar la DDN como parte de la desperonización de las Fuerzas Armadas. ${ }^{34}$ En el marco de la desactivación de la DDN se prestó mayo interés a formas de guerra no tradicionales, surgidas en el contexto de la Guerra Fría: la Guerra Atómica y la Guerra Revolucionaria. La gradual reconversión de la doctrina de defensa se inició en la Escuela Superior de Guerra (ESG), principal centro de formación teórico del Ejército, hacia 1957 bajo el impulso del entonces coronel Carlos Jorge Rosas, subdirector de la ESG, quien había estudiado en Francia entre 1953 y 1955. Los instructores franceses eran portadores de la nueva doctrina que estaba desarrollando su Ejército en base a la experiencia en las guerras coloniales en Indochina (1946-54) y Argelia (1954-1962).

Uno de los aspectos más destacados de este proceso de transformación doctrinario es que los asesores franceses daban conferencias sobre aquellos temas que se estaban discutiendo en la Ecole Superioure de Guerre de París. Además, en esos años, muchos oficiales argentinos viajaron a cursar en diferentes escuelas de

\footnotetext{
32 Vale recordar que en junio de 1973, Videla se negó a viajar en el avión que traía a Perón de regreso a la Argentina.

33 Los primeros asesores fueron los teniente coroneles Francois Pierre Badié y Patrice R. Jacobe de Nourois. Luego se incorporaron los teniente coroneles Robert Louis Bentresque y Jean Nougués. Sobre los asesores francesa véase Ernesto López, Seguridad Nacional..., Op.cit.pp.144-157; Samuel Amaral, "Guerra revolucionaria de Argelia a la Argentina, 1957-1962", Academia Nacional de la Historia, Investigaciones y Ensayos 48, Buenos Aires, 1998; Daniel Mazzei, Bajo el poder..., Op.cit., pp.131-143; Marie-Monique Robin, Escuadrones de la muerte. La escuela francesa, Buenos Aires, Sudamericana, 2005.

${ }^{34}$ Ernesto López, Seguridad nacional...., Op.cit., pp.130-133.
} 
formación. Cuando regresaban eran destinados en la Escuela Superior de Guerra o en la Escuela Superior Técnica donde transmitían lo que habían aprendido en los claustros parisinos. ${ }^{35}$

La influencia francesa en la ESG fue profunda. Algunos graduados de aquellos años, como los generales Ramón Camps o Acdel Vilas han escrito sobre el impacto de aquellas enseñanzas en su actuación represiva durante la década de 1970.36 Incluso el vocabulario utilizado por los militares argentinos tiene la impronta francesa. La emblemática expresión "lucha contra la subversión" ya aparece en algunos artículos publicados en la Revista de la ESG.

Por otra parte, en 1961, se realizó el primer curso interamericano de Guerra Revolucionaria, inaugurado por el presidente Frondizi, que contó con la presencia de militares de 14 países del continente, incluido los Estados Unidos. Para entonces el Estado Mayor había comenzado a organizar los primeros ejercicios de guerra contrarrevolucionaria ${ }^{37}$; y el entonces coronel Osiris Villegas, principal teórico de la Seguridad, escribió Guerra revolucionaria comunista, un verdadero manual sobre el tema que abrevaba en la experiencia francesa. ${ }^{38}$

Lo más destacado de este nuevo corpus doctrinario es que, a partir de la experiencia colonialista francesa, se piensa en un enemigo interno. Tras la derrota en Dien Bien Phu, en 1954, muchos oficiales franceses se dieron cuenta de que la guerra clásica, tal como la concebían, no existía más. Al enfrentarse a la guerrilla vietnamita empezaron a desarrollar una doctrina que se adaptara a esa nueva realidad. El más destacado fue el coronel Charles Lacheroy quien luego de vivir muchos años en el Lejano Oriente, regresó a París donde planteó que la guerra moderna había cambiado y que ahora el enemigo podía estar entre nosotros. Desarrolló la guerra psicológica e inició la escuela francesa de guerra contrarrevolucionaria a partir de la lectura atenta de los textos de Mao ${ }^{39}$. Según Lacheroy esta nueva forma de guerra se peleaba "en las mentes", por eso eran fundamentales la acción psicológica y la acción cívica. En términos militares la población era "el terreno" y las fronteras que separaban a los bandos ya no eran geográficas sino "ideológicas". En ese contexto obtener información para desarticular la estructura de la guerrilla se transformó en esencial. Esto llevó a la aceptación de la práctica de la tortura como medio para obtener esa información;

\footnotetext{
${ }^{35}$ Así Cándido Hure, Luis Tibiletti, Manrique Mom, Alcides López Aufranc y Edgardo Daneri fueron designados profesores y directores de la ESG luego de regresar de Francia. También realizaron cursos técnicos varios oficiales que alcanzarían el generalato durante la década de 1960. En el caso de López Aufranc fue enviado a Argelia como observador junto a toda la su promoción de la Ecole Superieure de Guerre. Daniel Mazzei, “La misión militar...”, Op.Cit., p.115, nota 24.

${ }^{36}$ Daniel Mazzei, Bajo el Poder..., Op.Cit., p.132.

37 Ya para entonces se empezó a utilizar las expresiones zonas, subzonas y áreas para compartimentar el territorio. Se trata de la forma que adopta en nuestro país el quadrillage (cuadriculado) utilizado por el Ejército francés para enfrentar al FLN argelino.

${ }^{38}$ Osiris Guillermo Villegas, Guerra revolucionaria comunista. Buenos Aires, Círculo Militar, 1962. Sobre esa misma temática pueden consultarse una serie de artículos del coronel Miguel Manrique Mom, en la Revista de la ESG.

${ }^{39}$ Sobre el coronel Charles Lacheroy véase Marie-Monique Robin, Escuadrones..., Op.Cit..
} 


\section{Lucha facciosa, autonomía e influencias externas en las Fuerzas Armadas argentinas en la segunda mitad del siglo $\mathrm{XX}$}

así como a la multiplicación los organismos de inteligencia, que generaron un mayor control sobre la población.

El fin de la influencia directa de Ejército francés se produjo hacia 1962, al tiempo que aumentaba el ascendiente del Pentágono. Entre las situaciones que confluyeron para provocar este "cambio de guardia" encontramos, la profunda crisis que afectaba a las Fuerzas Armadas francesas, empantanadas en la guerra de Argelia, que habían perdido todo criterio de jerarquía, subordinación y autoridad. Casi al mismo tiempo, Cuba se declaraba socialista, John F. Kennedy lanzaba su "Alianza para el Progreso", y el Pentágono modificaba su política hacia los países latinoamericanos con la creación del Colegio Interamericano de Defensa, la convocatoria a Conferencias de Ejércitos Americanos y, fundamentalmente, del crecimiento exponencial del número de oficiales latinoamericanos entrenados en bases militares de los Estados Unidos y el Canal de Panamá. ${ }^{40}$

En el marco de la Mutual Security Act y de la Foreign Assitance Act, Estados Unidos invirtió, entre 1946 y 1999, 4.386,2 millones de dólares en asistencia militar a países latinoamericanos, otorgados en calidad de préstamos y subsidios. Argentina recibió 275,2 millones de dólares (6,27\% del total). La mayor parte de estos fondos corresponden al período 1961-1977. Se estima que durante la Guerra Fría los Estados Unidos entrenaron casi 125.000 militares de países de América Latina y el Caribe. De los fondos destinados a subsidios para educación y entrenamiento de militares latinoamericanos Argentina -segunda fuerza militar del continenterecibió solo 17 millones de dólares (4,54\% del total). El monto de los subsidios, por lo tanto, no guarda relación con el tamaño de las fuerzas armadas sino con la cantidad de militares y miembros de fuerzas de seguridad que pasaron por diversos programas de entrenamiento en bases norteamericanas.

Unos 60.000 militares latinoamericanos fueron entrenados por cuenta del Pentágono en bases ubicadas en la zona del canal de Panamá durante la segunda mitad del siglo XX. De ese total sólo 598 eran argentinos. ${ }^{41}$ Pero más allá de la repercusión pública del entrenamiento en la Escuela de las Américas, los cursos más importantes y prestigiosos se realizaban en el territorio continental de los Estados Unidos. A diferencia de la Escuela de las Américas, los cursos en las escuelas de armas y servicios eran en inglés, tenían duración variable entre seis meses y un año y, en algunos casos, preveían la incorporación posterior a unidades del Ejército de

\footnotetext{
${ }^{40}$ La amenaza que representaba la expansión de la Revolución Cubana en el continente, aumentó la preocupación norteamericana por la "seguridad continental", llevó a afianzar la asistencia y la cooperación militar, privilegiando el entrenamiento de oficiales latinoamericanos en técnicas contrainsurgentes. Desde entonces, uno de los aspectos más importante de los programas de asistencia militar fue la educación y entrenamiento de personal militar latinoamericano en bases militares norteamericanas.

41 Durante la etapa más activa de la Escuela de las Américas (entre 1961 y 1977) se destacan los cursos vinculados a la Guerra Revolucionaria y la Contrainsurgencia. En los primeros años del período (1961-1964) la mayor parte del personal que viajó a Fort Gulick eran oficiales jefes (capitanes, mayores y teniente coroneles) que realizaban cursos de diez semanas, en Inteligencia Militar, Contrarrevolución y Operaciones Contrainsurgentes. En síntesis, de los 180 cursos realizados en ese período, 103 se vinculan con técnicas para la guerra contrainsurgente o antisubversiva.
} 
los Estados Unidos. ${ }^{42}$ También existieron otras formas de "cooperación" o "intercambio" fomentadas por el Pentágono. Una de ellas eran los viajes grupales que se hicieron muy comunes a partir de 1961. Decenas de militares argentinos recorrieron bases del Ejército norteamericano realizando seminarios, giras de operaciones, o visitas a Institutos militares de Estados Unidos y el Canal de Panamá.

La asistencia norteamericana no se limitó al entrenamiento de personal militar o visitas "de orientación". El Pentágono también organizó conferencias que reunían a los jefes de las distintas Fuerzas Armadas del continente. Estas conferencias, de las que solo participaba personal militar en actividad, fortalecieron la autonomía militar respecto del poder civil y fueron indiferentes de los golpes de estado que se sucedieron en la región a partir de 1962.43

A fines de la década de 1960 los militares argentinos empezaron a elaborar una doctrina propia que se ve reflejada en la elaboración de nuevos reglamentos. Ya no se trata de copiar reglamentos norteamericanos para la guerra contrarrevolucionaria sino reelaborar los propios en base a más de una década de experiencia y la integración de la influencia francesa y norteamericana. ${ }^{44}$ Esto significó el desarrollo de un "modelo argentino", cuyas particularidades serían la clandestinidad y la desaparición como sistema. Ese "modelo" fue exportado a Centroamérica en la segunda mitad de la década de 1970.45 Los militares argentinos se prestaron gustosos a asistir a dictaduras derechistas o a los "contras" nicaragüenses en sus batallas de esa tercera Guerra Mundial ${ }^{46}$, que como venían sosteniendo desde 1962, se libraba entre el Occidente Cristiano y el Oriente Ateo y Rojo.

\section{Algunas conclusiones}

42 El destino más prestigioso era la Escuela de Comando y Estado Mayor, en Fort Leavenworth (Kansas), considerado la cumbre de la educación militar norteamericana. Otro destino anhelado era el exclusivo Colegio Interamericano de Defensa ubicado en el Fort Lesley J. McNair (Washington D.C.), que funcionaba bajo el control y con el financiamiento de la OEA y de la Junta Interamericana de Defensa.

${ }^{43} \mathrm{Al}$ respecto, Ernesto López afirma que: “[...] si bien no es posible sostener que las Conferencias de Ejércitos Americanos hayan funcionado como usinas golpistas, sí, en cambio, jugaron un papel legitimador del avance de los militares sobre el poder político y sobre el control del aparato del Estado". Ernesto López, Seguridad nacional..., Op.Cit., p-.71.

${ }^{44}$ Sobre los reglamentos militares en este período véase Ana Sofía Jemio, "La construcción del enemigo interno en los reglamentos del Ejército Argentino de las décadas del sesenta y setenta. Continuidades y rupturas", X Jornadas de Sociología. Facultad de Ciencias Sociales, Universidad de Buenos Aires, Buenos Aires, 2013; y Esteban Pontoriero, "En torno a los orígenes del terror de Estado en la Argentina de la década del setenta. Cuándo, cómo y por qué los militares decidieron el exterminio clandestino", Papeles de Trabajo 10 (17), pp.30-50.

45 Ariel C. Armony, La Argentina, los Estados Unidos y la cruzada anticomunista en América Central, 1977-1984, Bernal, UNQ, 1999.

46 La idea de una tercera guerra mundial ya está planteada en los textos de Osiris Villegas o el coronel Miguel Manrique Mom, a comienzos de los años sesenta, pero alcanzaron su pleno desarrollo con el general Ramón Genaro Díaz Bessone, quien fuera comandante del Segundo Cuerpo en 1976. 


\section{Lucha facciosa, autonomía e influencias externas en las Fuerzas Armadas argentinas en la segunda mitad del siglo $X X$}

Como hemos visto en más arriba, el derrocamiento de Perón significó cambios profundos en las Fuerzas Armadas argentinas, y particularmente en el Ejército. En primer lugar la profunda depuración iniciada semanas después de que Lonardi asumiera la presidencia dejó a las Fuerzas Armadas en manos de oficiales profundamente antiperonistas por más de tres décadas. Esto no significó el fin de los conflictos internos ya que se desarrollaron una serie de luchas facciosas que culminaron, en 1963, con el triunfo del bando azul. Esto significó el predominio por una década del arma de caballería dentro del Ejército y el ocaso del poder que la Armada había adquirido desde septiembre de 1955. En la década de 1970, y a pesar de algunos breves intentos de cambio - como el liderado por Carcagno -, y de la creciente presencia de jóvenes oficiales peronistas en sus cuadros, las Fuerzas Armadas mantuvieron conducciones formadas en los lineamientos establecidos por la "Revolución Libertadora". Este modelo entró en una crisis terminal con el surgimiento de los grupos carapintadas, en la segunda mitad de la década de 1980, quienes responsabilizaron de la grave situación castrense a lo que denominaban las cúpulas "procesistas" y "liberales". El enfrentamiento entre estos dos sectores terminó debilitando a ambos y favoreció la consolidación de un sector "profesionalista" cuyas cabezas visibles fueron los generales Isidro B. Cáceres y Martín Balza.

Por otra parte la reacción contra los intentos de peronización de las Fuerzas Armadas y la creciente puja interna, así como los intentos de impedir el retorno del peronismo al poder generaron un aumento de los niveles de autonomía de las Fuerzas Armadas con respecto al poder político. Este cambio en la autonomía (ahora de carácter ofensivo y político) se expresó a través de los "planteos militares" que debilitaban a gobiernos de escasa legitimidad. A lo largo de dos décadas la autonomía militar creció, aunque no en forma progresiva ni lineal, sino con avances y retrocesos. Recién en 1975 los niveles de autonomía alcanzaron su punto culminante. Durante la última dictadura los militares fueron dueños de la vida y de la muerte de los argentinos. Sin embargo, su derrota en Malvinas marcó el comienzo del proceso de declinación del poder militar que lleva ya tres décadas.

La plena autonomía de las Fuerzas Armadas está íntimamente relacionada con la internalización de la doctrina de la Guerra Contrarrevolucionaria que sobredimensionó los organismos de inteligencia militar e impuso un mayor control sobre toda la población, la cual se convirtió en un enemigo potencial. Y puesto que al amparo de esta doctrina sólo la vigilancia permanente podía hacer que la Nación fuera impenetrable a la "infiltración comunista", crecieron y se multiplicaron los servicios de inteligencia y la cantidad de oficiales entrenados en el exterior en rubros relacionados con esta temática. La preocupación por cuestiones vinculadas con la seguridad interna originó lo que Alfred Stepan llama "nuevo profesionalismo de la seguridad interna" 47 , que contribuyó a expandir en forma autoritaria lo que los

\footnotetext{
${ }^{47}$ Alfred Stapan, Repensando a los militares en política. Cono Sur: un análisis comparado, Buenos Aires, Planeta, 1988, pp.30-31.
} 


\section{Daniel Mazzei}

militares consideraban su rol en el sistema político, ocupando nuevas funciones y ejerciendo nuevas prerrogativas. El aparato de inteligencia que surgió como consecuencia de la internalización de la doctrina que planteaba la existencia de un Enemigo Interno se transformó, en la segunda mitad de la década de 1970, en un núcleo autónomo dentro de unas Fuerzas Armadas autónomas.

\section{Bibliografía}

Alfred Stapan, Repensando a los militares en política. Cono Sur: un análisis comparado, Buenos Aires, Planeta, 1988.

Ana Sofía Jemio, "La construcción del enemigo interno en los reglamentos del Ejército Argentino de las décadas del sesenta y setenta. Continuidades y rupturas", $\mathrm{X}$ Jornadas de Sociología. Facultad de Ciencias Sociales, Universidad de Buenos Aires, Buenos Aires, 2013.

Ariel C. Armony, La Argentina, los Estados Unidos y la cruzada anticomunista en América Central, 1977-1984, Bernal, UNQ, 1999.

Daniel Mazzei, «Soldados de Perón. Los jóvenes oficiales del Ejército y el Peronismo durante la "Revolución Argentina"», Nuevo Mundo Mundos Nuevos [En ligne], Questions du temps présent, mis en ligne le 18 septembre 2015. URL: http://nuevomundo.revues.org/68192

Daniel Mazzei, "Carcagno, el Comandante que no fue", Cuadernos del Sur, Historia 40, 2011, pp.139-157.

Daniel Mazzei, "La élite del Ejército argentino (1962-1973)", Cuadernos de Marte / Año 3, $\mathrm{N}^{\circ} \quad 4, \quad$ julio 2013, págs. 93-125. http://webiigg.sociales.uba.ar/revistacuadernosdemarte/nro4/4 mazzei.pdf

Daniel Mazzei, "Reflexiones sobre la transición democrática argentina”, PolHis, Año IV, no7 (primer semestre de 2011), págs.8-15.

Daniel Mazzei, “Tiempo de revancha: la desperonización del Ejército durante la Revolución Libertadora”, en Taller, № 12, abril de 2000.

Daniel Mazzei, Bajo el poder de la caballería. El Ejército Argentino (1962-1973). Buenos Aires, Eudeba, 2012.

Ernesto López y David Pion Berlin, Democracia y cuestión militar. Bernal, Universidad Nacional de Quilmes, 1996. 


\section{Lucha facciosa, autonomía e influencias externas en las Fuerzas Armadas argentinas en la segunda mitad del siglo $\mathrm{XX}$}

Ernesto López, El primer Perón. El militar antes que el político. Buenos Aires, Capital intelectual, 2009.

Ernesto López, Ni la ceniza ni la gloria. Actores, sistema político y cuestión militar en los años de Alfonsín. Bernal, Universidad Nacional de Quilmes, 1994.

Ernesto López, Seguridad nacional y sedición militar. Buenos Aires, Legasa, 1987.

Esteban Pontoriero, "En torno a los orígenes del terror de Estado en la Argentina de la década del setenta. Cuándo, cómo y por qué los militares decidieron el exterminio clandestino", Papeles de Trabajo 10 (17), pp.30-50.

Eugenio Kvaternik, Crisis sin salvataje: la crisis político-militar de 1962-1963. Buenos Aires, Ides, 1987.

Guillermo O’Donnell, “Modernización y golpes militares. Teoría, comparación y el caso argentino”, Desarrollo Económico, Vol.12, N47, octubre-diciembre de 1972.

Jorge Perren, Puerto Belgrano y la Revolución Libertadora. Buenos Aires, Solaris editores, 1997.

Juan Francisco Guevara, Argentina y su sombra. Buenos Aires, edición del autor, 1973.

Marie-Monique Robin, Escuadrones de la muerte. La escuela francesa, Buenos Aires, Sudamericana, 2005.

Osiris Guillermo Villegas, Guerra revolucionaria comunista. Buenos Aires, Círculo Militar, 1962.

Prudencio García, El drama de la autonomía militar. Buenos Aires, Alianza,1995.

Robert Potash, El Ejército y la política en Argentina (1945-1962). Buenos Aires, Sudamericana, 1981.

Rosendo Fraga, El Ejército y Frondizi (1958-1962). Buenos Aires, Emecé, 1992.

Samuel Amaral, "Guerra revolucionaria de Argelia a la Argentina, 1957-1962", Academia Nacional de la Historia, Investigaciones y Ensayos 48, Buenos Aires, 1998.

Recibido: $17 / 10 / 2016$

Evaluado: $27 / 11 / 2016$

Versión Final: 26/12/2016 